\title{
ASSESSMENT OF THE SEISMIC RETROFITTING OF A HISTORICAL MASONRY MOSQUE BY MEANS OF NONLINEAR DYNAMIC ANALYSIS
}

\author{
ABIDE AŞIKOĞLU ${ }^{1 *}$, LUIS C. SILVA ${ }^{1}$, ÖZGÜR AVŞAR ${ }^{2}$, AND \\ PAULO B. LOURENÇO
}

${ }^{1}$ Institute for Sustainability and Innovation in Structural Engineering (ISISE)

University of Minho

Azurém, 4800-058 Guimarães, Portugal

e-mail: abideasikoglu@hotmail.com, luisilva.civil@gmail.com,pbl@civil.uminho.pt - http://isise.net

(*corresponding author)

${ }^{2}$ Department of Civil Engineering, Eskisehir Technical University
26555 Eskişehir, Turkey
e-mail: ozguravsar@eskisehir.edu.tr - http://insaat.eskisehir.edu.tr

Keywords: Historical Masonry, Seismic retrofitting, Finite Element Method, Nonlinear dynamic analysis

\begin{abstract}
Seismic actions have been a great challenge for structures in the structural engineering community, and the need for further developments has been approved by catastrophic seismic events at each time. Reproducing the dynamic behavior of structures with an acceptable level of accuracy is a complex task due to uncertainties related to the geometrical, material and physical structural system, more particularly, in the case of existing historical masonry structures. The use of dynamic analysis is a better choice than the use of static or quasi-static approaches since it is a better representation of the dynamic response of a structure by taking account of its energy dissipation capacity. The scope of the present paper is focused on a seismic assessment of a historical masonry structure, Kütahya Kurşunlu Mosque located in Turkey, before and after it has been retrofitted. The historical mosque is located in a seismic prone zone where it is crucial to ensure seismic safety of structures and the local community. Based on the condition of the structure reported from the site inspections, a seismic retrofitting by using steel girder elements was implemented on the structural load-bearing walls. The effectiveness of the seismic retrofitting to the seismic response of the mosque was investigated by means of the finite element method. Three bi-directional nonlinear dynamic analyses were performed by using real ground motion records aiming at the validation of the nonlinear dynamic response of the numerical model in terms of damage patterns, and demonstration of the contribution of the seismic retrofitting by comparing the representative model with its retrofitted counterpart. The comparison has been carried out in terms of peak displacement and damage patterns. It is found that the contribution of the seismic retrofitting is considerable for the out-of-plane displacements of the load-bearing walls. Furthermore, a good correlation between existing damage and the numerical damage is achieved, and, therefore, the validation of the nonlinear response of the representative model is attained.
\end{abstract}




\section{INTRODUCTION}

Throughout the history, national and cultural identity of society has been declared by means of tangible and intangible cultural heritage. The Nara Document (1994) emphasizes that "The protection and enhancement of cultural heritage and heritage diversity in our world should be actively promoted as an essential aspect of human development". Architectural heritage, i.e. tangible cultural heritage, is the most concrete example of a culture that defines identity to the community where it belongs, and, also, its legacy shares a particular creative quality, uniqueness, originality, and authenticity that makes it a universal heritage of humankind (Jokilehto, 1999). Furthermore, historic areas have been a catalyst for the regeneration of their environment and contribute to the economy of cities (Orbaşl1, 2007). Therefore, conservation of historical structures is significant to be conducted according to the principle of minimum intervention, as admitted in ICOMOS (2013). Ancient structures have unique architectural, material and structural properties owing to their complex geometry, variety in construction materials, and, changes due to repair works, long-term effects, or damage (Roca (2006)). In this sense, case-based solutions need to be developed for conservation, strengthening, and retrofitting of heritage structures. Moreover, the seismic performance of such buildings is highly dependent on its heterogeneous material distribution, sophisticated geometric features, limited information regarding the connections between structural components, building condition under long-term effects, and absence of global structural behavior (Lourenço et al., 2011). The present study investigates a historical masonry mosque located in Turkey which is

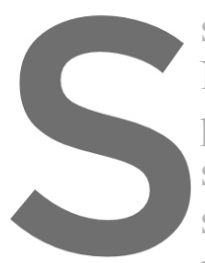
situated in the Alpine-Himalayan Seismic Belt
North Anatolian Fault (NAF), East Anatolian
prediction of an earthquake by day and tin
significant information. For instance, NAF is
sequence as shown in Figure 1. The sequen resulting in $360 \mathrm{~km}-1$ ength surface rupture
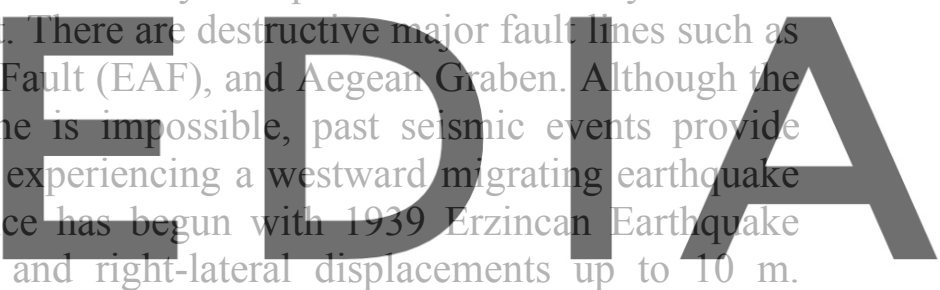
Following events happened in 1942 (M7.1, with $50 \mathrm{~km}$ rupture), 1943 (M7.7, with $280 \mathrm{~km}$

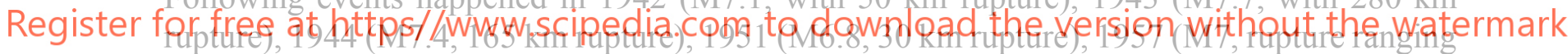

between $30-50 \mathrm{~km}$ ), 1967 (M7.2, $80 \mathrm{~km}$ rupture), and finally, two earthquakes happened in 1999 (IVI7.5, $130 \mathrm{~km}$ rupture and $\mathrm{M} 17.1$, with $50 \mathrm{~km}$ of rupture)[4]. Consequentiy, approximately $1,000 \mathrm{~km}$ fault unzipped starting from Erzincan nearly to the Marmara Sea [4]. Rockwell (2013) [4] states that a similar earthquake sequence happened a century ago was concluded regarding the paleo-seismic site works and it is found that the current sequence, which has started in 1939, has not completed yet. Therefore, another destructive earthquake is expected in the Marmara Sea close to İstanbul in which 15 million people live. In addition, the western part of the country is expected to be affected.

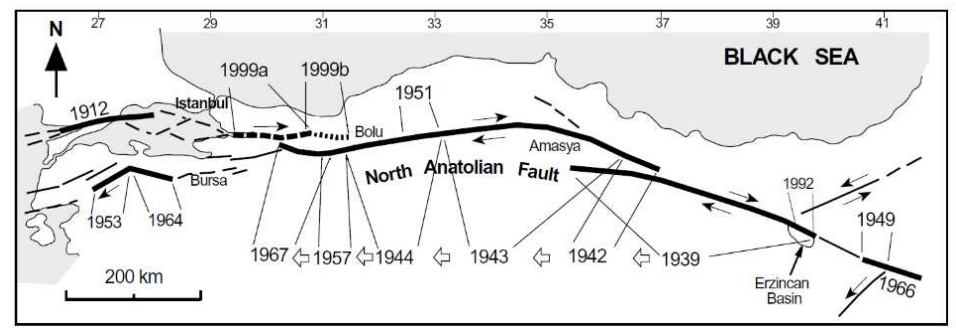

Figure 1. The westward migrating earthquake sequence along the NAF starting from 1939 [5] 
It is obvious that it is crucial to minimize the effects of earthquakes on the structures in order to ensure the social and economic concerns of the society. However, the protection of heritage structures still requires significant developments and collapse or severe damage of any structure which promotes value for the society that should be prevented against earthquake actions. Turkey has been home to many civilizations throughout history and consequently, the culture of the country has been influenced and shaped by those periods of time. Therefore, there is a wide range of cultural and built heritage belonging to different eras of time which forms Turkey's outstanding legacy of heritage. For instance, Turkey has 17 properties inscribed on the UNESCO World Heritage List, and, additionally, 71 historical sites have been nominated in the Tentative List of UNESCO World Heritage. In fact, the General Directorate of Cultural Heritage and Museums of the Republic of Turkey Ministry of Culture and Tourism stresses that there is approximately 107,000 immovable cultural property that requires preservation and protection all around the country. Immovable heritage properties are defined according to their service whereas types of the built heritage have been specified as a sample of civil architecture, religious, cultural, governmental, military, industrial, commercial structures, cemeteries, ruins, memorials and monuments, and, protected streets. Several cities with a high number of immovable built heritage are listed in Table 1. The vast majority of the heritage construction has been recorded in İstanbul, with nearly 31,000, followed by İzmir, Bursa, Ankara, and Kütahya. It is emphasized that the given cities are only some that have high seismic activity. Obviously, the majority of the architectural heritage is under seismic risk.

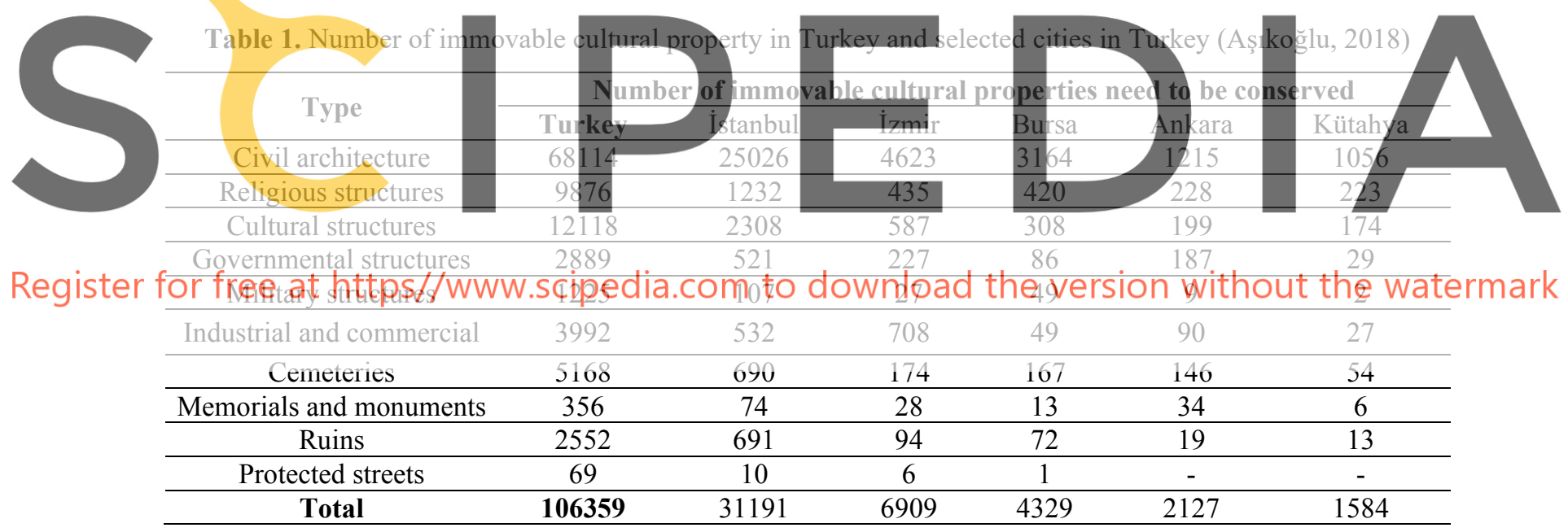

\section{HISTORICAL KÜTAHYA KURȘUNLU MOSQUE}

Construction of Kütahya Kurşunlu Mosque dates back to 1377-1378, using ruins of a preexisting building, and the Mosque suffered several conservation and restoration interventions between the $13^{\text {th }}$ and $19^{\text {th }}$ centuries. Although the mosque is standing for centuries, it is inevitable that the structure has experienced human and natural originated damage during its life span. In 2013, the Directorate General of Foundations of Turkey started restoration works and seismic retrofitting actions on the Mosque to address architectural and structural concerns. Thus, the present work examines the seismic behavior of the Mosque-located in Kütahya province with a high seismic exposition - before and after it has been retrofitted. 
Kütahya Kurşunlu Mosque is located in the residential area of the city and being detached. The Mosque has a rectangular plan with a length of $13.0 \mathrm{~m}$ and a width of $9.3 \mathrm{~m}$ (Figure 2). The highest element of the Mosque is the minaret, with a height of $28.0 \mathrm{~m}$, and it has a rectangular base with a polygonal transition section to a circular body. In the main body, the height of the load-bearing walls, which were constructed as three-leaf masonry, and the top point of the dome are $7.8 \mathrm{~m}$ and $11.0 \mathrm{~m}$, respectively. The construction material of the Mosque is cut stone and brick, and the outer layer of the walls was built with cut stone, whereas rubble stone was used for the inner layer and core of the load-bearing walls. The dome, which is restrained by an octagonal drum, the vaults, pendentives, and octagonal drum were constructed using brick. The minaret base and circular body are constituted with cut stone and brick, respectively.
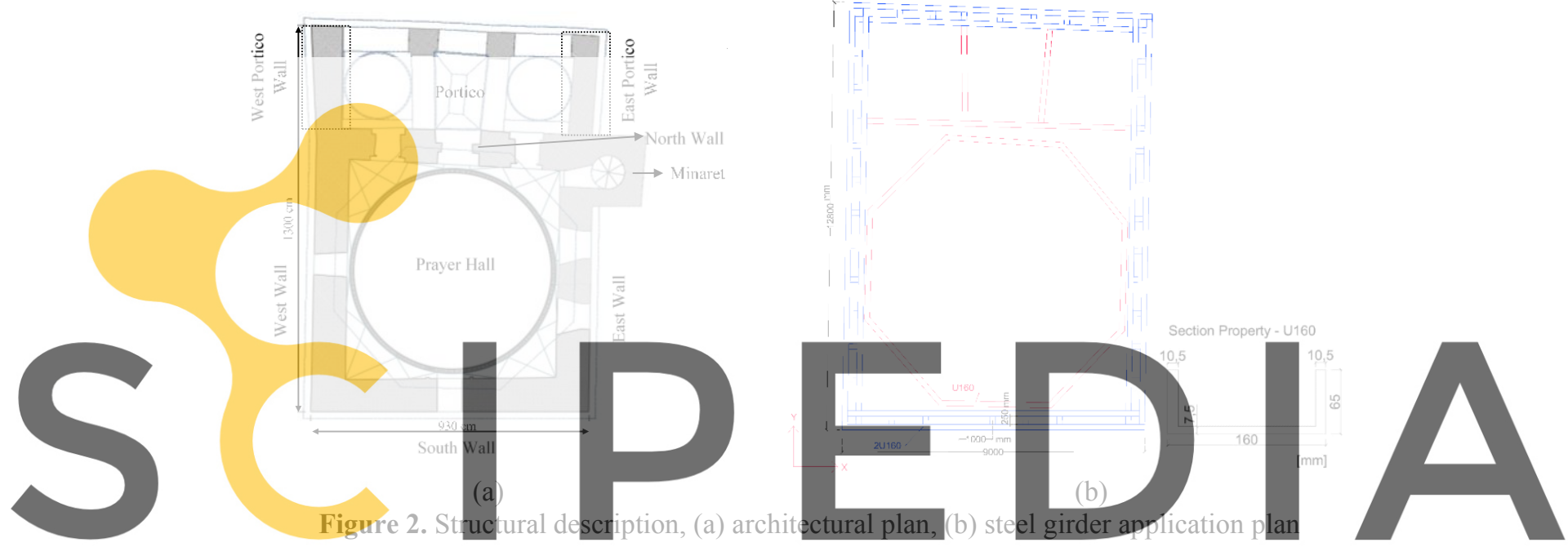

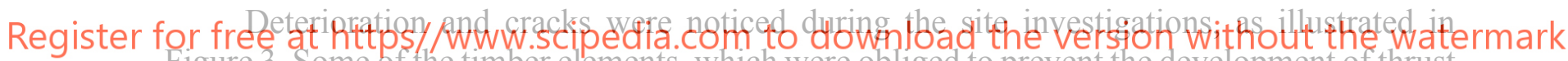
Figure 3. Some of the timber elements, which were obliged to prevent the development of thrust at the arch elements, were deteriorated and some of them were missing. Additionally, loss of wooden tie beams, that was supposed to be located inside the load-bearing walls along the length, was reported. Various moderate vertical cracks were noticed mainly around the window openings and at the intersection of two perpendicular walls. Moreover, moderate damage was observed on the octagonal drum and the dome, both at the interior and exterior surfaces. It is possible to say that the response of the structure and, also the dome seem to be dominated by out-of-plane mechanisms and expansion of the octagonal drum due to lack of global structural behavior. Based on the observed damage on the Mosque, it was decided to implement steel girder retrofitting having a cross-section of U160, at the top level of the load-bearing walls to achieve a better interaction between the walls (Figure 4). The connection between the steel elements and the masonry walls were provided by steel anchor. Additionally, steel elements were also inserted to the base section and top of the drum walls whereas timber elements were used to be found. In this part, the steel elements were placed, welded, and then, the gap between the elements and the masonry was filled with hydraulic lime-based mortar. 

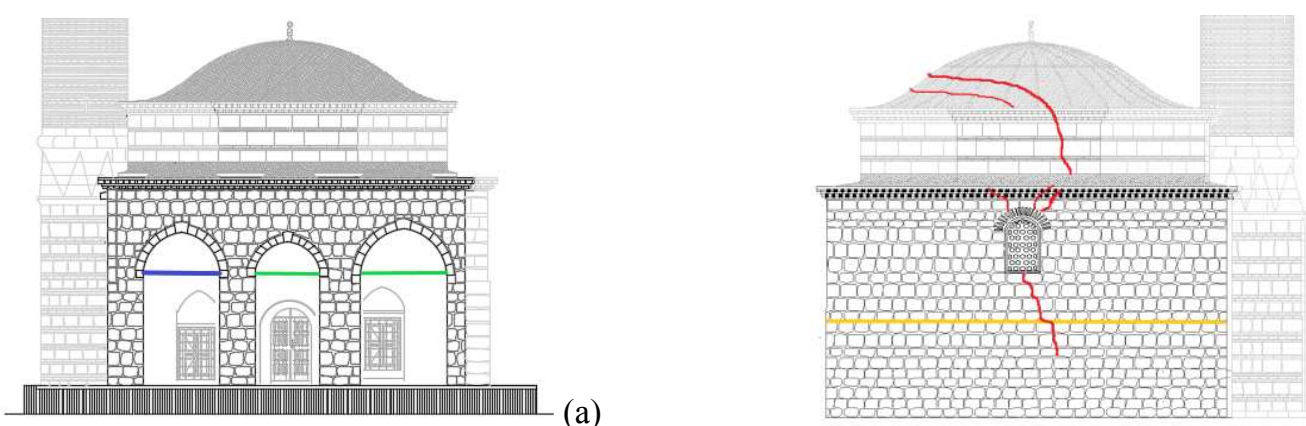

(b)

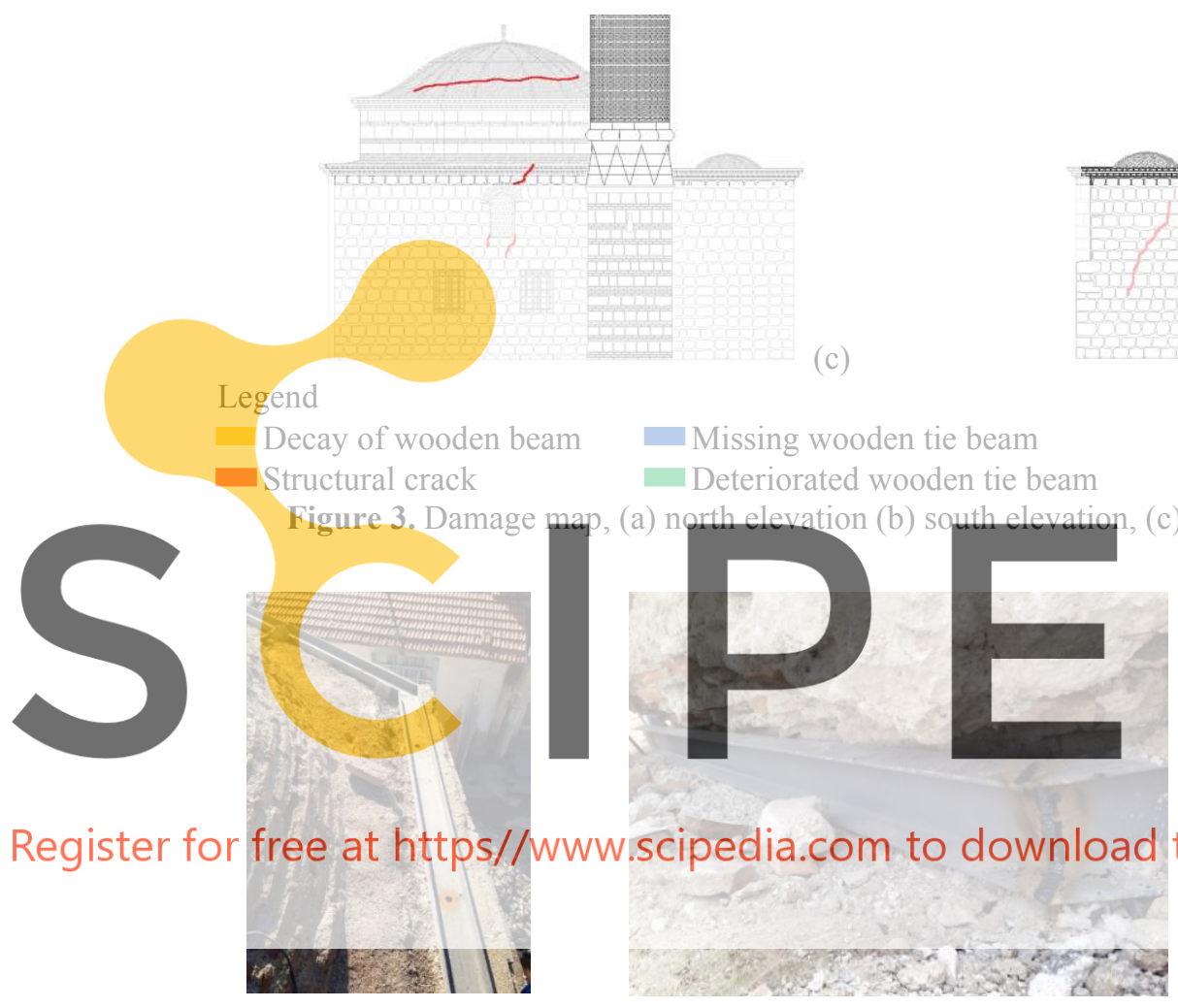

(a)

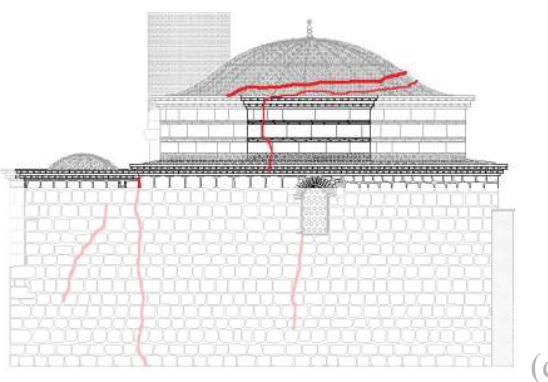

(d)

Figure 4. Application of single steel girder (U160) at the top and bottom of the drum, and double steel girder (2U160) on the load-bearing walls

\section{REPRESENTATIVE NUMERICAL MODEL}

An optimized numerical model of the Mosque was prepared by using FX+ for DIANA [6]. The representative model was constructed as a continuum element model assuming homogenous material behavior throughout the structure [7]. The finite element model created using beam, shell, and solid elements. Steel girder elements in the retrofitted model are represented by a set of beam elements $(\mathrm{L} 13 \mathrm{BE})$ while shell elements (triangular T15SH) are used to model the load-bearing walls, arcades, dome, and drum. On the other hand, a tetrahedron (TE12L) solid elements were used to model the pendentives since they have a complex volume. The continuum model of the retrofitted Mosque has 27,250 elements, having 428 beam, 22,978 shell, and 3844 solid elements, with a total number of 12,892 nodes and 72,950 degrees of 
freedom. The degrees of freedom located at the foundation of the structural system was assumed as fully fixed. A detailed description of the numerical model is given in [8]. The constitutive model of the masonry material was assigned as a total strain fixed crack model that has been applied in several studies, such as [9] and [10]. The tensile behavior is defined by exponential stress-strain relation in the post-peak regime while compressive behavior is assumed to be parabolic for both pre- and post-peak response [11]. The material properties are listed in Table 2. The detailed description of the material properties is given in [8]. Accordingly, calibration of the continuum model was carried out by changing the Young's modulus of masonry material considering the results obtained from Operational Modal Analysis. Thus, the modal response of the representative model is given in Figure 5.

Table 2. Mechanical properties of the materials

\begin{tabular}{cccccccc}
\hline Material & $\gamma\left(\mathrm{t} / \mathrm{m}^{3}\right)$ & $\mathrm{E}(\mathrm{MPa})$ & $\begin{array}{c}v(\text { Poisson } \\
\text { ratio })\end{array}$ & $\begin{array}{c}\text { Compressive } \\
\text { strength } \\
\left(\mathrm{f}_{\mathrm{c}}\right)[\mathrm{MPa}]\end{array}$ & $\begin{array}{c}\text { Tensile } \\
\text { strength } \\
\left(\mathrm{f}_{\mathrm{t}}\right)[\mathrm{MPa}]\end{array}$ & $\begin{array}{c}\text { Compressive } \\
\text { fracture energy } \\
\left(\mathrm{G}_{\mathrm{c}}\right)[\mathrm{N} / \mathrm{mm}]\end{array}$ & $\begin{array}{c}\text { Tensile fracture } \\
\text { energy } \\
\left(\mathrm{G}_{\mathrm{t}}\right)[\mathrm{N} / \mathrm{mm}]\end{array}$ \\
\hline Cut Stone & 2.1 & $1500^{*}$ & 0.2 & 2.6 & 0.1 & 4.2 & 0.012 \\
\hline Brick & 2.0 & $2500^{*}$ & 0.2 & 6.0 & 0.1 & 9.6 & 0.012 \\
\hline Timber & 0.7 & 11000 & 0.3 & - & - & - & - \\
\hline Steel & 7.85 & 200000 & 0.3 & 235 & 235 & - & - \\
\hline
\end{tabular}

*Obtained from dynamic identification

It is important to mention that the non-retrofitted model, in terms of geometrical and material properties, is the same as the retrofitted model, the only difference being the existence of the steel girders on the latter model. In fact, frequencies, mode shapes, and cumulative mass
participation ratios of the non-retrofitted model are quite similar to the retrofitted finite element
model, and there is no signifidant change in modal response, as expected. Therefore, the pon-
retrofitted model was used to represent the nonlinear response of the non-retrofitted condition
of the Mosque before the damge. The damage was not considered in the numerical modeldue to the limited information about the internal damage and the lack of representativeness.

Register for free at https//www.scipedia.com to download the version without the watermark

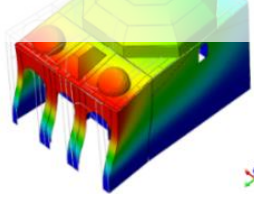

$f_{\text {num }}=5.77 \mathrm{~Hz}$

(a)

Sum_Mx $(\%)=60.72$

Sum_My $(\%)=0.00$ (b) $f_{\text {num }}=7.87 \mathrm{~Hz}$

Sum Mx $(\%)=61.13$

Sum My $(\%)=66.95$ (c)

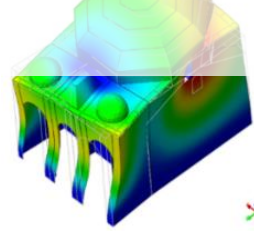

$f_{\text {num }}=9.77 \mathrm{~Hz}$

Sum_Mx $(\%)=70.80$

Sum_My $(\%)=67.27$

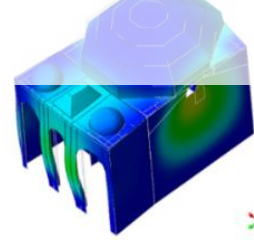

$f_{\text {num }}=11.32 \mathrm{~Hz}$

(d)

Sum_Mx $(\%)=70.83$

Sum My $(\%)=67.28$

Figure 5. The modal response of the first four modes, (a) $1^{\text {st }} \overline{\text { mode, }}$ (b) $2^{\text {nd }}$ mode, (c) $3^{\text {rd }}$ mode, (d) $4^{\text {th }}$ mode

\section{NONLINEAR DYNAMIC ANALYSIS}

In order to perform the dynamic analyses, three ground motions recorded from past earthquakes occurred in Turkey were used. The location of the epicenter of each selected earthquake and its ground motions' seismological properties are given in Table 3 . The vertical component of the earthquakes was disregarded, and both horizontal components of each input motions were applied orthogonally to the global coordinate axes of the mosque. The transverse components of Erzincan and Bolu records and longitudinal component of Bingöl record were 
performed in the transversal direction $(+X)$ of the mosque while the rest of the input were acted in the longitudinal direction (+Y) (Figure 6). The application of the orthogonal components was decided through the weaker axis according to the spectral acceleration values for the first mode of vibration period. The response spectra of the input motions and the elastic design spectra defined in TEC 2007 are given in Figure 7. The viscous damping ratio required for the Rayleigh damping strategy was assumed as 3\%. Due to the fact that nonlinear time history analyses require high computational effort, only a part of the strong ground motions was considered in order to reduce the computation time. Thus, the duration of each record was shortened according to the cumulative energy duration [13] and only the first $20 \mathrm{~s}$ of each acceleration time series were considered. The seismic performance of the retrofitted and non-retrofitted mosque was studied by means of bidirectional nonlinear time history analyses using the HilberHughes-Taylor method ( $\alpha$-method). The numerical procedure was carried out using the secant method and energy norm convergence criteria with a tolerance value of 0.001 to solve dynamic equilibrium solution at each iteration. Accordingly, the effectiveness of the seismic retrofitting was investigated and presented in terms of out-of-plane displacements and principal tensile strain distribution on the structure.

Table 3. Seismological properties of selected ground motions (TR-NSMN)
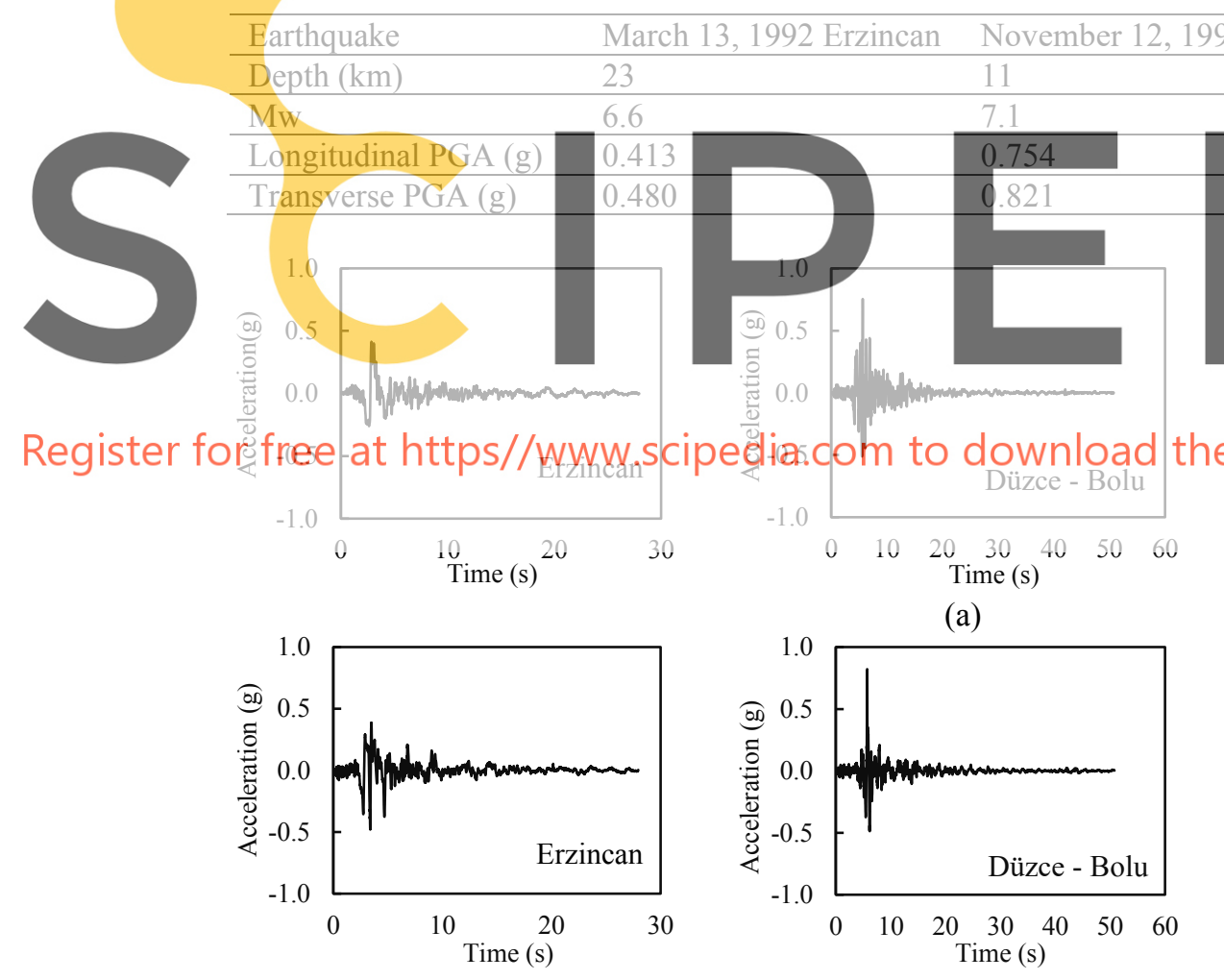

999 Düzce $\quad$ May 1, 2003 Bingöl
$\frac{6}{6.3}$

(a)
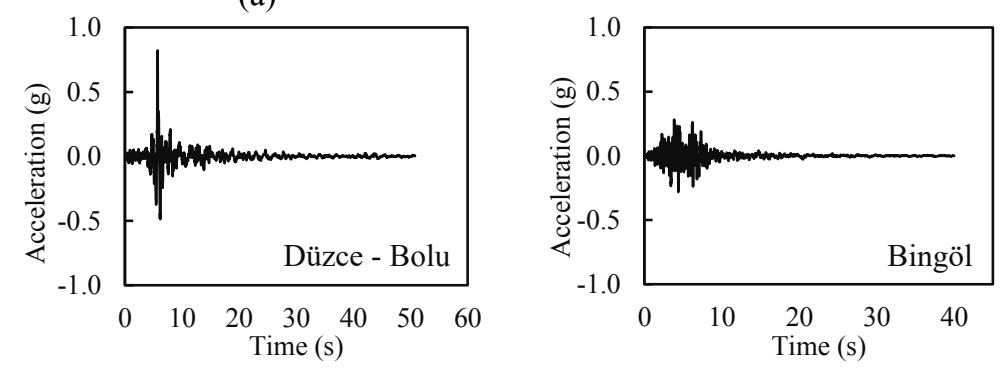

(b)

Figure 6. Acceleration-time series (TR-NSMN), (a) longitudinal (N-S), (b) transversal component (E-W)

Displacement response of the non-retrofitted and retrofitted model is given in Figure 8 and Figure 9 for the out-of-plane direction of the investigated structural walls, transversal (X) direction for East and West wall, longitudinal (Y) direction for South and North wall. It is found that two nodes located on the parallel walls have similar trends, but residual displacements are 
in the opposite direction from their origin. Notwithstanding, the results obtained from the retrofitted model exhibit that improvement in the global structural behavior is achieved due to the fact that the residual displacement is considerably reduced. Indeed, the steel girder retrofitting contributes to the seismic response. In general, a considerable decrease in the peak displacement was observed in the Erzincan and Bingöl Earthquake cases. However, it is important to notice that although there is a reduction in the peak displacement, for instance as a result of the Düzce-Bolu Earthquake, the imposed displacement values are still high and might be an indication of structural damage. Reduction in the out-of-plane displacements on the East and West walls is nearly up to 55\% while the difference in the South and North Wall reach $86 \%$ and $66 \%$, respectively. Above all, the expansion of the dome is reduced significantly by implementing the seismic retrofitting, as shown in Figure 10.

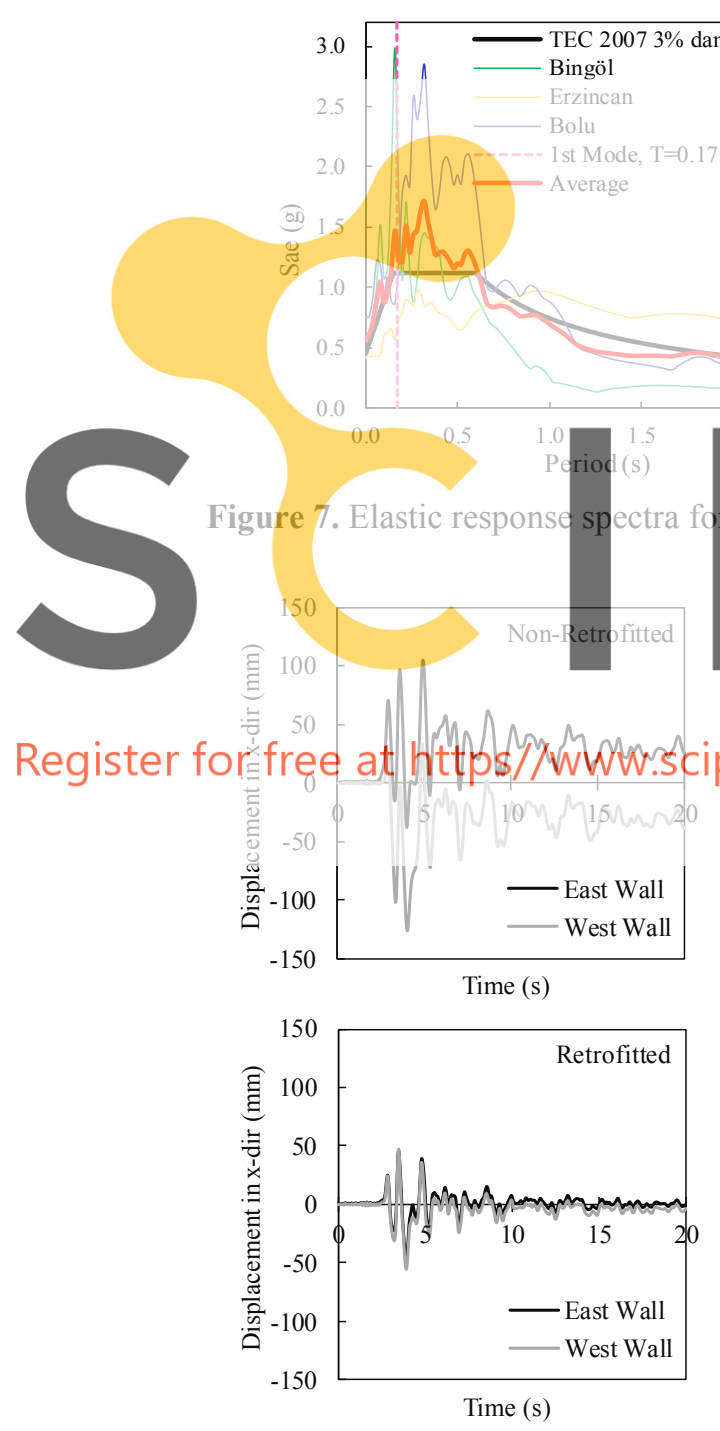

(a)
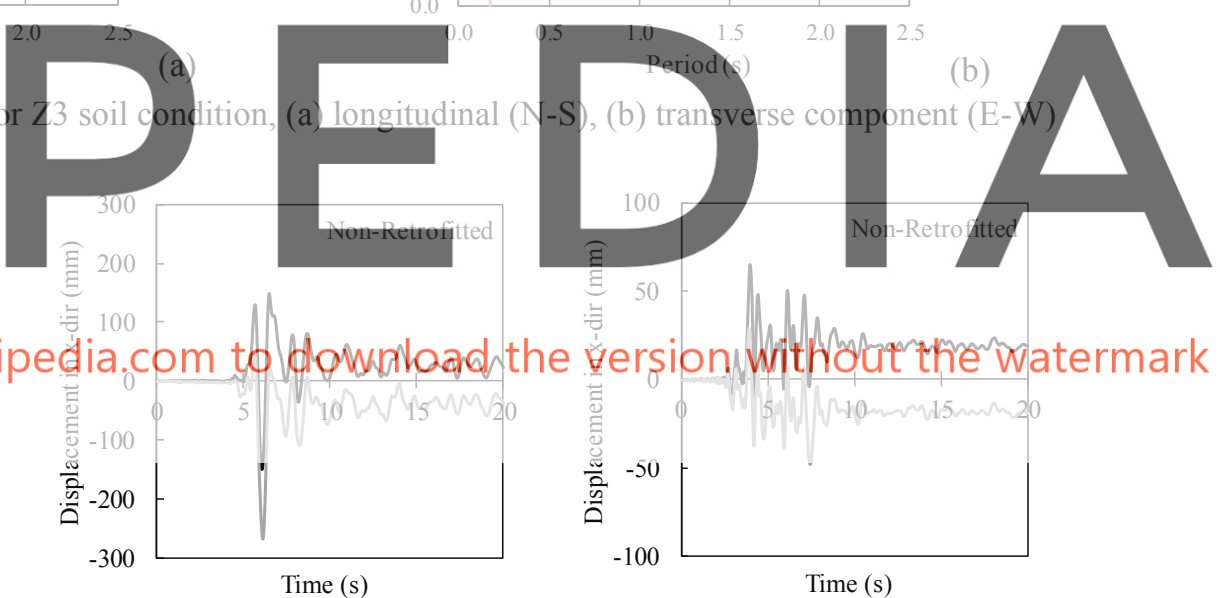

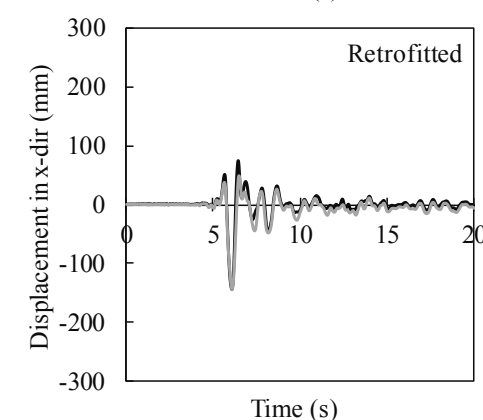

(b)

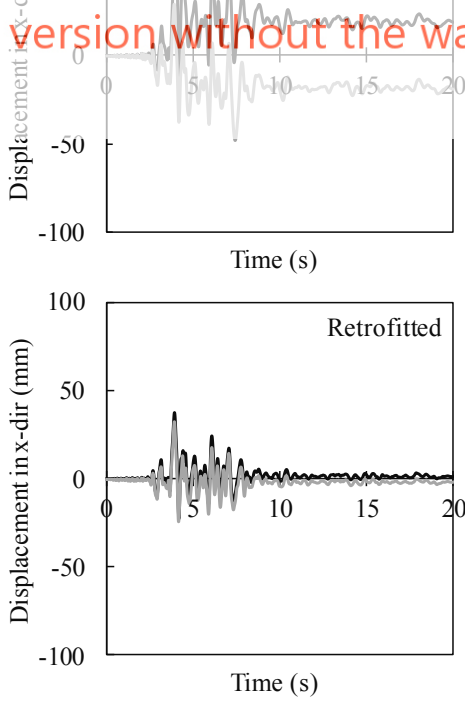

(c)

Figure 8. Displacement response at east and west walls in the x-direction, (a) Erzincan, (b) Düzce, (c) Bingöl 

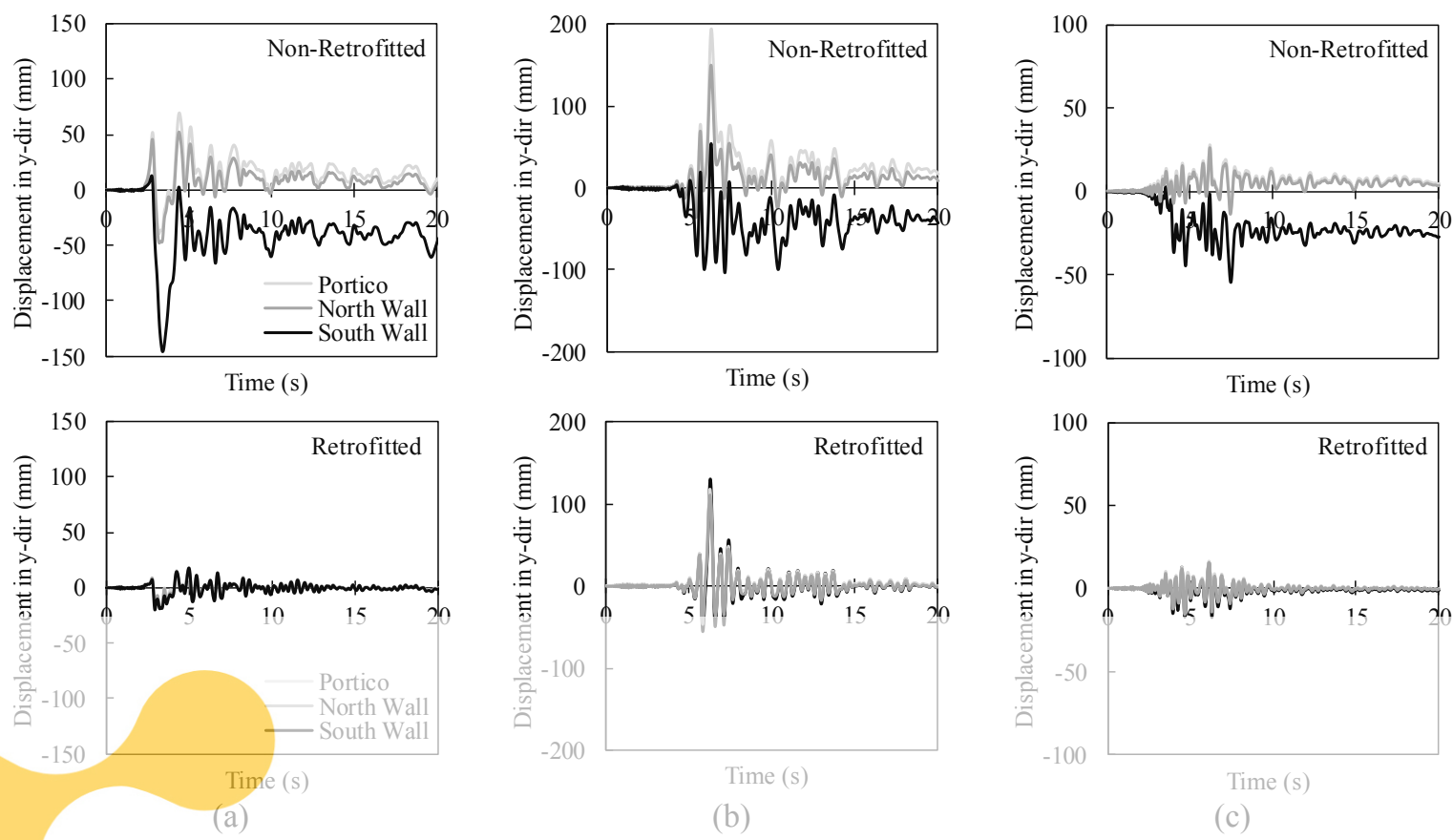

Figure 9. Displacement response at north and south walls and portico in the y-direction, (a) Erzincan, (b) Düzce, (c) Bingöl
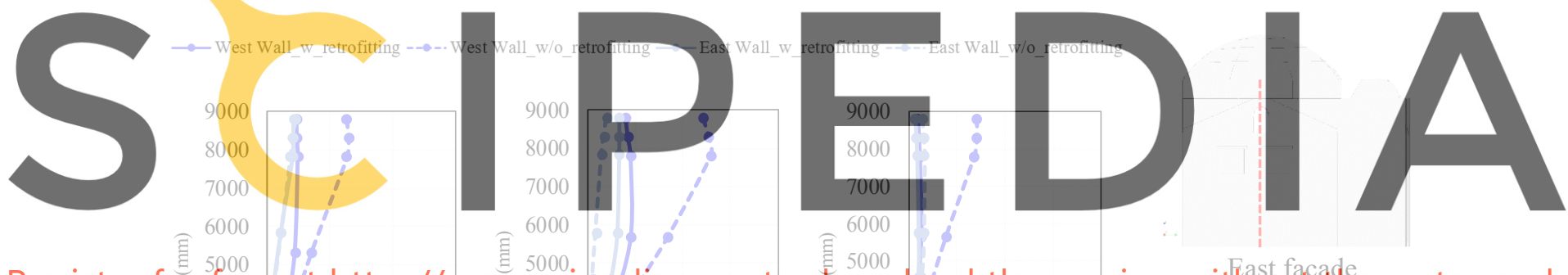

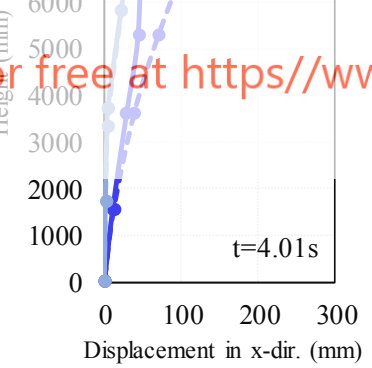

(a)

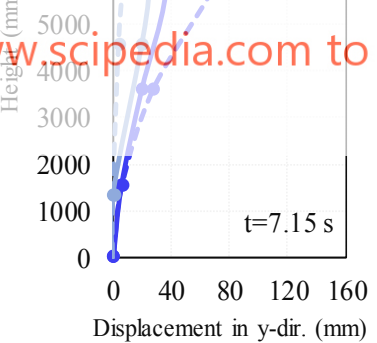

(b)

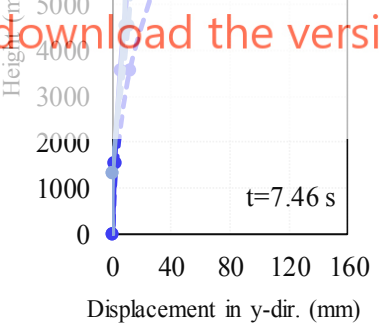

(c)

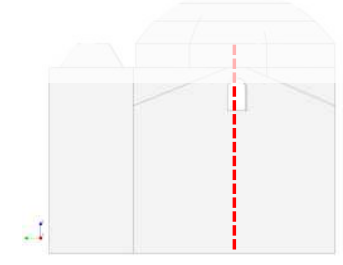

West façade

(d)

Figure 10. Change in absolute displacement in the out-of-plane direction, at time-step when the west wall has peak displacement, (a) Erzincan, (b) Düzce - Bolu, (c) Bingöl, (d) location of the section cuts

According to [15], the principal tensile strain distribution is a good qualitative damage indicator. A fictitious homogenous material is adopted and, therefore, the strain values observed on the numerical model does not correspond to the values that are expected on the real structure. In this regard, strain distribution of the structural response was analyzed at the time step in which the peak displacement was achieved on each structural component (see [16]). In the present paper, the most critical plots are presented in Figure 11, Figure 12, and Figure 13. Numerical simulation satisfactorily reproduced a crack pattern similar to the existing one. In 
particular, the numerical damage observed on the South Wall and the dome are compatible with the moderate crack found on the real structure. According to the difference in strain distributions of two models, the effect of steel girder retrofitting on seismic response is observed. The non-retrofitted structure is dominantly subjected to vertical cracks, i.e. out-ofplane behavior, resulting in high tensile stresses on the significant portion of the structure. Nevertheless, change in damage patterns is noticed and can be an indication of the limitation of out-of-plane response. Still, even with the retrofitting, the structure experiences damage depending on the dynamic input.
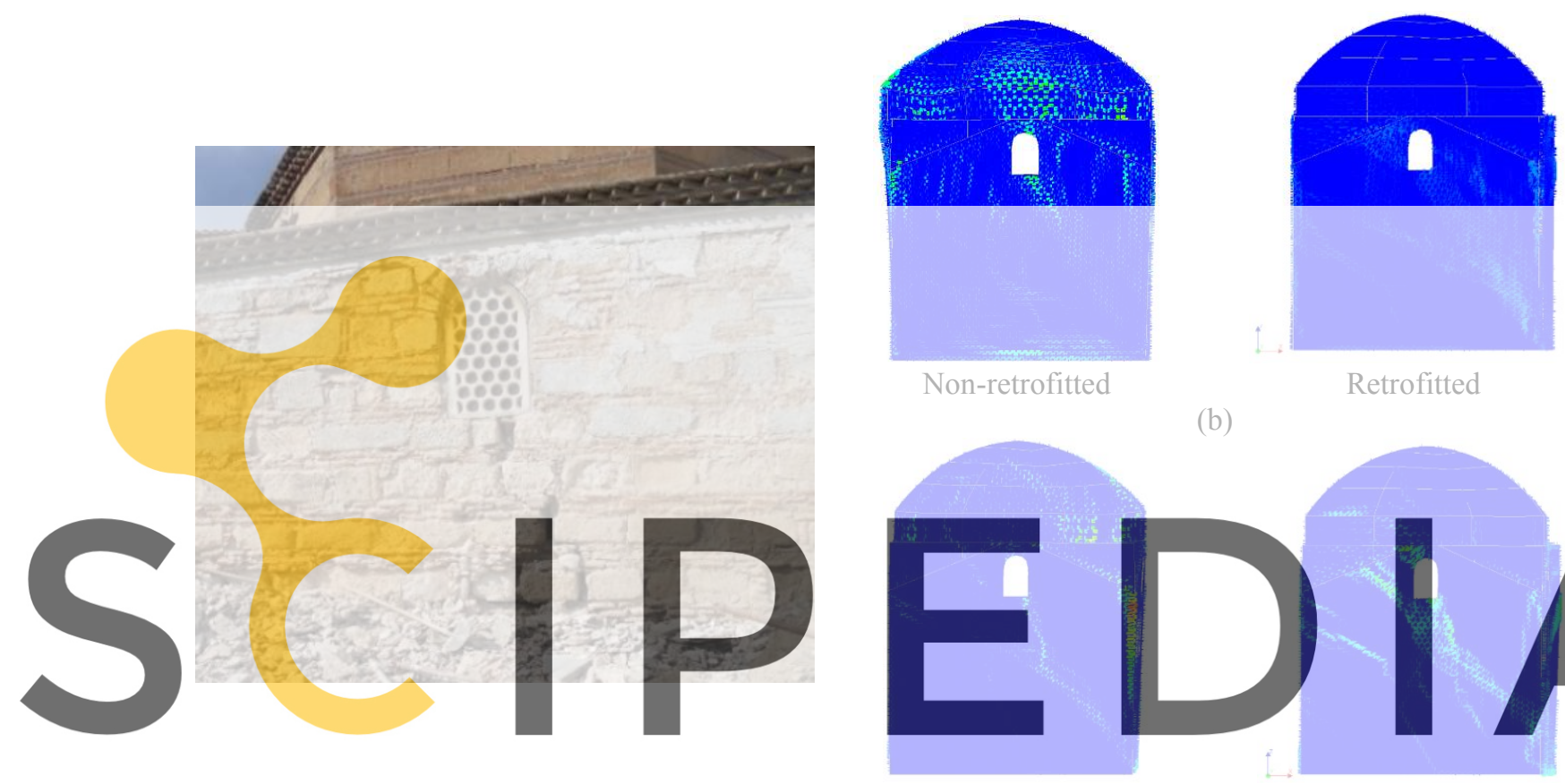

Register for free at https/(awww.scipedia.com to downiftofittecthe verssion withofit the watermark

Figure 11. Correlation of (a) real damage; and total principal tensile strain distribution on the south façade, (b) Erzincan Earthquake at time-step 3.43s, (c) Bingöl Earthquake at time-step 3.99s

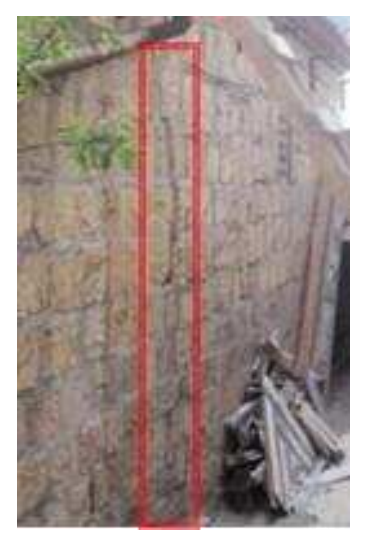

(a)

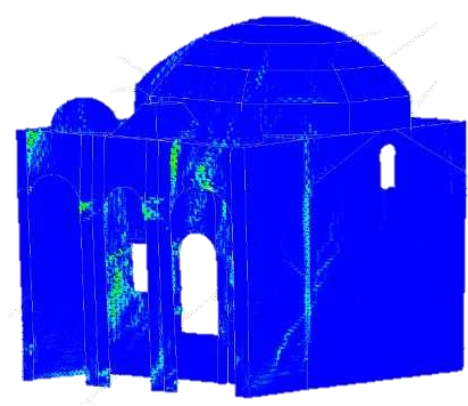

(b)

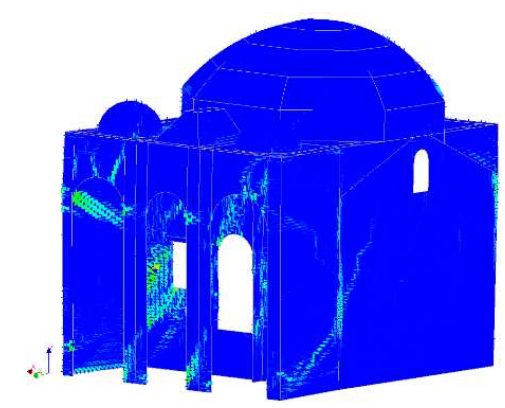

(c)

Figure 12. Correlation of (a) real damage, and total principal tensile strain distribution on the west façade subjected to the Bingöl Earthquake, at time-step 3.99s, (b) non-retrofitted, (c) retrofitted 


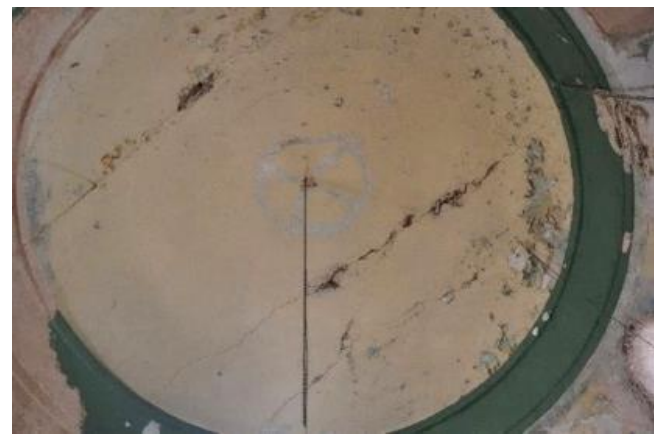

(a)

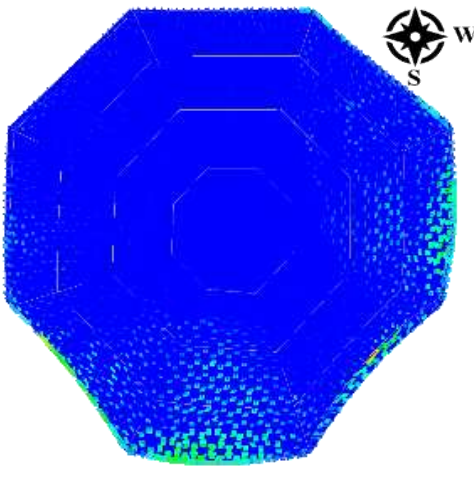

Non-retrofitted

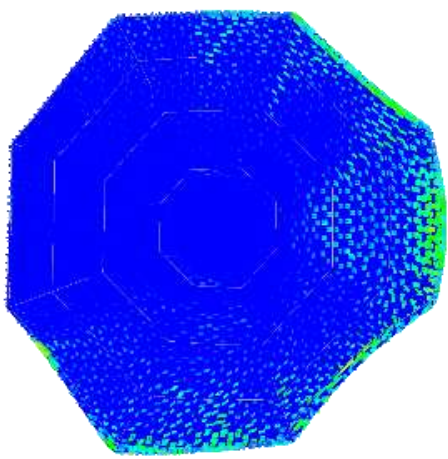

(b)
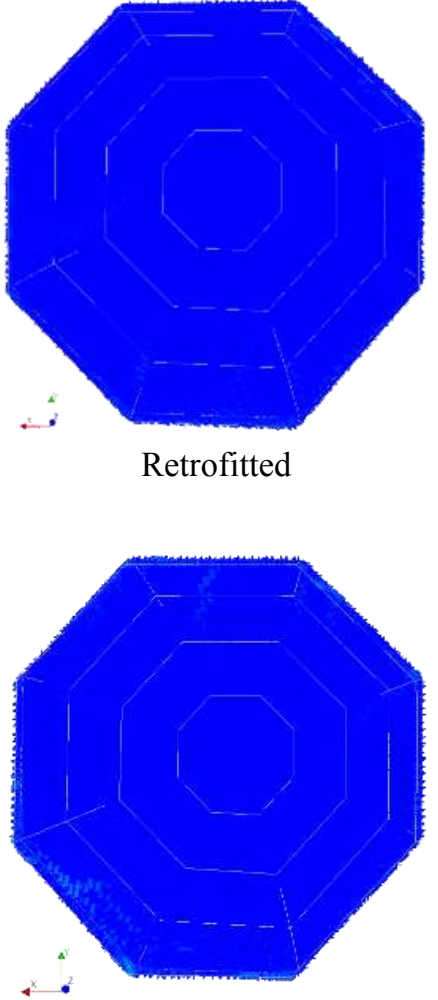

(c)

Figure 13. Correlation of the crack patterns, (a) real damage; total principal tensile strain distribution on the dome (b) the Erzincan Earthquake at time-step 3.43s, (c) the Bolu Earthquake at time-step 6.12s

\section{CONCLUSIONS}

In the present study, a historical masonry mosque, namely Kütahya Kurşunlu Mosque was investigated. Severe damage was observed on the mosque and several interventions and retrofitting actions were carried out. Regarding the site observations, severe damage can be attributed to the lack of connections and integrity of the overall system. Within this context, steel girder elements were introduced to the structure and anchored at the top of the load-bearing walls, and, bottom and top level of the octagonal drum (dome support). In order to study the effectiveness of the introduced retrofitting technique, the finite element method was used. The nonlinear dynamic analysis was conducted by using three different real ground motions in which both horizontal components of the accelerograms were used. According to the analysis results, the model without the retrofitting experiences high residual displacements whereas, in the retrofitted model, the imposed residual displacements are limited. Thus, the steel girders are effective in what concerns the out-of-plane behavior providing the so-called box behavior for the historical structure. The validation of the performed analysis can be made by considering the non-retrofitted model. Once the damage is known for this case, numerical damage verifies the constituted hypotheses. Therefore, the response of the retrofitted case obtained from the numerical analysis is assumed to be representative of the actual response. 


\section{REFERENCES}

[1] ICOMOS, "ICOMOS Turkey Architectural Heritage Conservation Charter," 2013.

[2] P. Roca, "The study and restoration of historical structures: From principles to practice," in Structural Analysis of Historical Constructions, 2006, pp. 9-24.

[3] P. B. Lourenço, N. Mendes, L. F. Ramos, and D. V. Oliveira, "Analysis of masonry structures without box behavior," Int. J. Archit. Herit., vol. 5, no. 4-5, pp. 369-382, 2011.

[4] T. Rockwell, "North Anatolian Fault," in Encyclopedia of Natural Hazards, P. T. Bobrowsky, Ed. Springer, 2013, pp. 738-739.

[5] H. . Akyüz et al., "Surface Rupture and Slip Distribution of the 12 November 1999 Düzce Earthquake (M 7.1), North Anatolian Fault, Bolu, Turkey," Bull. Seismol. Soc. Am., vol. 91, no. 1, pp. 61-66, 2002.

[6] FX + for DIANA, "Midas FX+ for DIANA, Customized Pre/Post-processor for DIANA.” MIDAS Information Technology Co., Ltd., 2013.

[7] P. B. Lourenço, "Computations on historic masonry structures," Prog. Struct. Eng. Mater., vol. 4, no. 3, pp. 301-319, 2002.

[8] A. Aşıkoğlu, Ö. Avşar, P. B. Lourenço, and L. C. Silva, "Effectiveness of seismic retrofitting of a historical masonry structure: Kütahya Kurşunlu Mosque, Turkey," Bull. Earthq. Eng., vol. 17, no. 6, pp. 3365-3395, 2019.

[9] L. C. Silva, N. Mendes, P. B. Lourenço, and J. Ingham, "Seismic Structural Assessment of the Christchurch Catholic Basilica, New Zealand," Structures, vol. 15, pp. 115-130, 2018.

[10] N. Mendes and P. B. Lourenço, "Sensitivity analysis of the seismic performance of ancient masonry buildings," Eng. Struct., vol. 80, pp. 137-146, 2014.

[11] DIANA FEA, “User's Manual Release 10.2." The Netherlands, 2017.

[12] TEC, "Turkish Earthquake Code: Specifications for the Buildings to be Constructured in Disaster Areas," in Official Gazette No 26454, 2007.

[13] M. D. Trifunac and A. G. Brady, "A study on the duration of strong earthquake ground motion," Bull. Seismol. Soc. Am., vol. 65, no. 3, pp. 581-626, 1975.

[14] TR-NSMN, "Strong Motion Database," AFAD. [Online]. Available: kyhdata.deprem.gov.tr.

[15] N. Mendes, "Seismic Assessment of Ancient Masonry Buildings : Shaking Table Tests and Numerical Analysis," PhD Thesis, University of Minho, 2012.

[16] A. Aşıkoğlu, "Numerical Investigation on the Effectiveness of Seismic Retrofitting of a Historical Masonry Mosque," MSc Thesis, Anadolu University, 2018. 